\title{
ROCK GRADE CONTROL STRUCTURES AND STEPPED GABION WEIRS: SCOUR ANALYSIS AND FLOW FEATURES
}

\author{
By Stefano Pagliara $^{1^{*}}$, Michele Palermo ${ }^{2}$ \\ 1* Corresponding Author, Prof., Department of Civil Engineering, University of Pisa, 22, Via \\ Gabba, 56126, Pisa, Italy, +390502217717, s.pagliara@ing.unipi.it \\ ${ }^{2} \mathrm{Ph}$. D., Department of Civil Engineering, University of Pisa, 22, Via Gabba, 56126, Pisa, Italy, \\ +390502217929, michele.palermo@ing.unipi.it
}

\begin{abstract}
Rock and stepped gabion weirs are peculiar hydraulic structures that received relatively little attention in technical literature. Nevertheless, they can be successfully used for river restoration instead of traditional hydraulic structures. They have the advantage of being elastic structures and to preserve the natural environment. They can easily adapt to the "in situ" conditions and can be effortlessly modified according to the different hydraulic or geometric conditions which can occur in a natural river. The present study aims to analyze the effects of their presence on flow pattern and on the scour hole occurring downstream. The analysis involved scour processes, hydraulic jump types, stilling basin morphology and flow patterns. Two different hydraulic jump types were distinguished and classified. It was shown that the flow regime deeply influences the scour process, which evolves much more rapidly when a Skimming Flow regime takes place. Empirical relationships are proposed to evaluate maximum scour depth, maximum axial length and non dimensional axial profiles.
\end{abstract}

Key-words: Flow pattern, Hydraulic jump, Rock, Scour, Stepped Gabion, Weir. 


\section{INTRODUCTION}

Natural river restoration is of fundamental importance for correct environmental management. In the last few decades, it has also become more and more important to harmonize the presence of man made structures with the necessity to preserve the natural contexts while minimizing flood risk. Hydraulic structures contribute to regulate global sediment threshold as they change the river bed slope and the flow conditions. Thus a correct design of a river restoration structure has to take into consideration several aspects. Particularly, the most important for river engineers are the flow features and the scour process. This last aspect has to be taken into consideration as it can lead to the collapse of the structure itself.

In the literature, the scour mechanism has been reasonably developed for the most common hydraulic structures, i.e. check dams, weirs, aprons, block ramps. A comprehensive work on scour downstream of grade control structures was conducted by Bormann and Julien (1991). They conducted both a theoretical and experimental analysis using large scale models. The scour process downstream of grade control structures was further developed by D'Agostino and Ferro (2004). Applying the incomplete self-similarity theory, they derived several non-dimensional groups upon which the scour mechanism mainly depends.

A detailed and complete analysis of the scour process downstream of an apron was conducted among others by Dey and Westrich (2003), Dey and Sarkar (2006a), Dey and Sarkar (2006b) and Dey and Raikar (2007). In particular, Dey and Westrich (2003) conducted experiments in the presence of a cohesive bed downstream of an apron. The authors proposed a complete and detailed analysis of the phenomenon taking into consideration the time variation of the scour hole geometry. Dey and Sarkar (2008) further developed the study of the submerged jets characteristics downstream of an apron, during the scour hole evolution, concluding that, in the scour hole, the flow is self-preserving.

The scour phenomenon due to plunging jets was also carefully taken into consideration as it can cause huge scour holes downstream of dams, resulting in a high structural risk for the dam 
itself. This phenomenon was analyzed in particular by Breusers and Raudkivi (1991) and Hoffmans and Verheij (1997) who collected a vast amount of data and reported both empirical and theoretical relationships present in literature. Another important parameter for scour processes is the stilling basin material uniformity whose effect was analyzed by several authors (among others Dey and Raikar 2005, Pagliara and Palermo 2008, and Pagliara et al. 2009).

Nevertheless, the understanding of the flow pattern and behaviour on the structure itself is a relevant element to be considered. In particular, the analysis of the hydraulic characteristics of the flow on block ramps was deepened by Pagliara and Chiavaccini (2006) and Pagliara et al. (2008). In addition, a comprehensive description of the flow and sediment patterns in the stilling basin, also in the case of expanded pools and live-bed, was furnished by Pagliara et al. (2009), Pagliara and Palermo (2011) and Pagliara et al. (2011), who extended the hydraulic jump classification proposed by Bremen and Hager (1993) for mobile beds.

The analysis of flow characteristics on the structure showed that the flow is mainly influenced by the geometry of the structure. Both high slope and stepped configuration have a fundamental importance in the air entrainment process. In particular, stepped chutes received a great attention as they are commonly used as energy dissipators in dam engineering. According to Chanson (1994), the flow regimes occurring on a stepped spillway can be Nappe Flow, Transition Flow and Skimming Flow. The first studies gave just rough transitional values by which one can distinguish the onset condition for Skimming Flow (among these Rajaratnam 1990, Essery and Horner 1978, Peyras et al. 1992). Recently, a detailed analysis of flow characteristics has been proposed by several authors, among these Chanson (1996), Othsu et al. (2000), Ohtsu et al. (2001), Boes and Hager (2003) and Ohtsu et al. (2004).

However, there is a lack of knowledge relative to the hydraulics of rock gabion weirs and rock grade control structure, in the presence of a downstream mobile stilling basin. In addition, studies present in the literature analyze only the flow characteristics on the structure, without taking into 
consideration the effect of submergence and the scour process downstream of the structure itself (see for example Peyras et al. 1992, Chinnarasri et al. 2008 and Mohamed 2010).

The present paper aims to analyze both the rock grade control structures and the stepped gabion weirs, varying the submergence conditions and the inflow discharge. The analysis was conducted in order to understand the flow behaviour on the structure itself and downstream of it. Moreover, all tests were conducted in the presence of a movable stilling basin, for different structure configurations. The scour morphology was studied in detail for all tested configurations and analytical relationships, to foresee the main scour hole dimensions, are proposed.

\section{EXPERIMENTAL APPARATUS AND METHOD}

Two models have been built in the laboratory: one simulating the rock grade control structure (Fig. 1a-b) and the other simulating the stepped gabion weir (Fig 2a-b). Figures 1a-b and 2a-b show the main hydraulic and geometric parameters: $Q$ is the discharge, $H$ the structure height, $h$ the upstream water depth measured from the horizontal plane passing through the top of the structure, $h_{0}$ the downstream water depth, $z_{\max }$ the maximum scour hole depth, $z_{M}$ the dune height, $l_{s}$ the axial scour hole length, $x$ and $z$ are the longitudinal and vertical coordinates, respectively. 0 is the origin of the coordinate system. The channel used for the simulation has the following geometric characteristics: $0.30 \mathrm{~m}$ wide, $0.60 \mathrm{~m}$ deep and $6 \mathrm{~m}$ long.

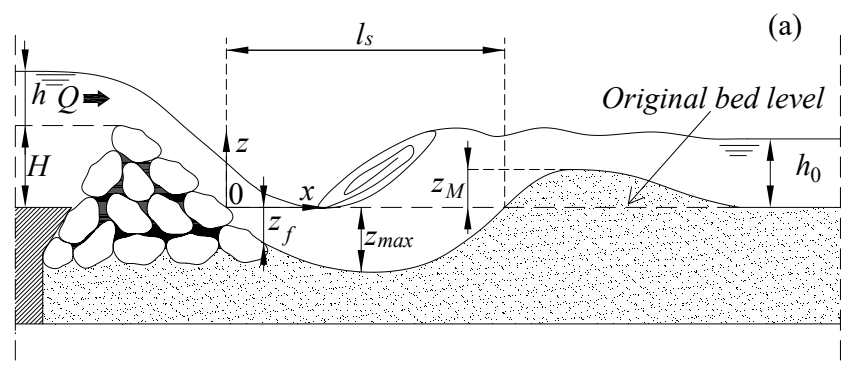




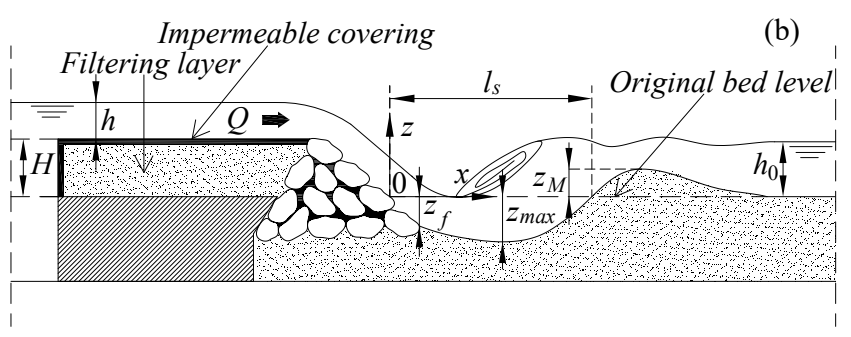

Figure 1 Diagram sketch of the rock grade control structure with the indication of the main geometric and hydraulic parameters: (a) without upstream filtering layer and (b) with upstream filtering layer

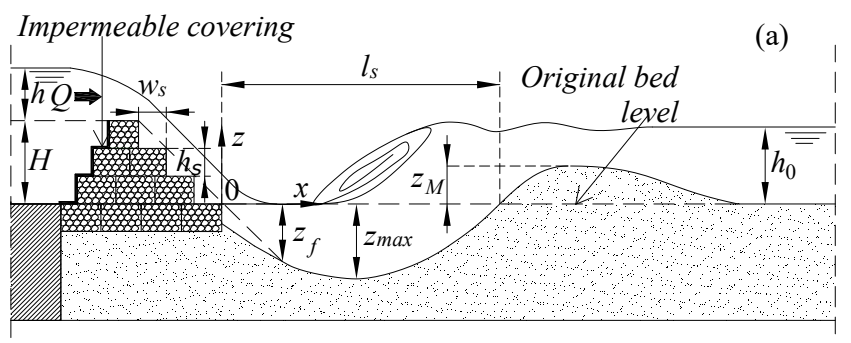

Impermeable covering

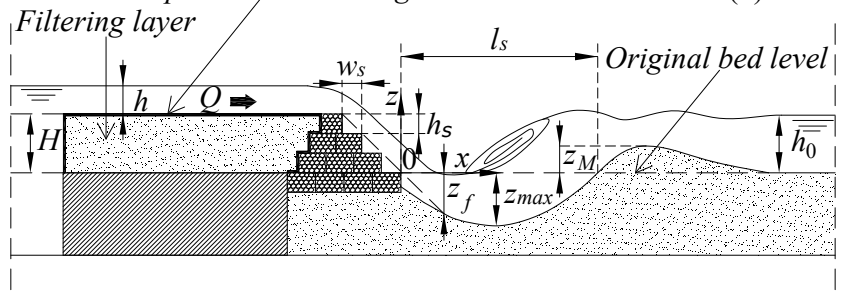

Figure 2 Diagram sketch of the stepped gabion weir with the indication of the main geometric and hydraulic parameters: (a) without upstream filtering layer and (b) with upstream filtering layer

The rock grade control structure was made of uniform crushed rock $\left(D_{50} \cong 7 \mathrm{~cm}\right)$. The structure was made by superimposed rock layers, and two different structure heights $H$ (measured from the original bed level) were tested, i.e. $H=10.3 \mathrm{~cm}$ (grade control structure $B 1$ ) and $H=13.7 \mathrm{~cm}$ (grade control structures $B 2$ ). The rocks were located in such a way that the slope of the downstream face of the structure was $45^{\circ}$. For both $B 1$ and $B 2$ structures, the rocks were linked together using a silicon glue, thus their permeability is negligible (Fig. 1a).

Upstream of the structure, three different configurations were tested and they are synthetized in Table 1. In particular, several experiments were conducted locating a sediment layer upstream of the rock grade control structure. Two different configurations (see Fig. 1b) were tested for the filtering layer, i.e. with and without an impermeable covering on it ( $B_{f}$ and $B_{f-\text { imp }}$, respectively). 
Thus, for $B_{f}$ there was infiltration of water in the granular material of the upstream layer, whereas for $B_{\text {fimp }}$ there was no infiltration. The filtering layer had the same height of the structure. The granular material in the filtering layer was the same used for the channel bed and its granulometric characteristics are $d_{50}=4.78 \mathrm{~mm}, d_{90}=5.7 \mathrm{~mm}$, non uniformity coefficient $\sigma=\left(d_{84} / d_{16}\right)^{0.5}=1.2$ and density $\rho=2645 \mathrm{~kg} / \mathrm{m}^{3}$, where $d_{x x}$ is the granular material diameter for which $x x \%$ is finer. A prismatic box, made of an iron net having $2 \mathrm{~mm} \times 2 \mathrm{~mm}$ square holes, was used in order to retain the filtering material.

The stepped gabion weir was made of rounded uniform stones $\left(d_{50}=1.2 \mathrm{~cm}\right)$. The total height of the structure was $H=15.4 \mathrm{~cm}$ and it was made by different superimposed layers of prismatic gabions. An iron net with square holes $1 \mathrm{~cm}$ x $1 \mathrm{~cm}$ was used to allow water flow while retaining the granular material. The layers were shaped in such a way that the resulting steps dimensions were $w_{s}=h_{s}=5.13 \mathrm{~cm}$, in which $w_{s}$ and $h_{s}$ are the length and the height of the steps, respectively. Thus the slope of the pseudo-bottom of the structure was $45^{\circ}$ (see Fig. 2a-b).

Also in this case, four different configurations were tested and they are synthetized in Table 1. Experiments were conducted adopting the configurations illustrated in Fig. 2a and for two different configurations of the upstream structure surface: 1) without any impermeable steel covering on the upstream part of the structure $\left(G W_{0}\right)$, and 2) with an impermeable steel covering on the upstream part of the structure $\left(G W_{i m p}\right)$. The impermeable steel covering did not allow upstream water infiltration in the structure.

Other experiments were conducted locating a filtering layer upstream of the structure. Also in this case, two different filtering layer configurations were tested: 1) with impermeable steel covering on both the upstream structure surface and filtering layer $\left.\left(G W_{f-i m p}\right), 2\right)$ without any impermeable steel covering $\left(G W_{f}\right)$. 
Table 1 Structures characteristics and relative number of tests $(\mathrm{A}=\mathrm{absent} ; \mathrm{P}=$ present $)$

\begin{tabular}{|c|c|c|c|c|c|c|c|}
\hline Structure & Symbol & Subscript & $\begin{array}{c}\mathrm{H} \\
{[\mathrm{cm}]}\end{array}$ & $\begin{array}{c}\text { Upstream } \\
\text { filtering layer }\end{array}$ & $\begin{array}{l}\text { Impermeable } \\
\text { covering on the } \\
\text { structure }\end{array}$ & $\begin{array}{c}\text { Impermeable } \\
\text { covering on upstream } \\
\text { filtering layer }\end{array}$ & $\begin{array}{l}\text { Number } \\
\text { of tests }\end{array}$ \\
\hline \multirow{4}{*}{$\begin{array}{l}\text { Rock grade } \\
\text { control } \\
\text { structure }\end{array}$} & $B 1$ & - & 10.3 & A & - & - & 7 \\
\hline & $B 2$ & - & 13.7 & $\mathrm{~A}$ & - & - & 13 \\
\hline & $B$ & $f$ & 13.7 & $\mathrm{P}$ & - & $\mathrm{A}$ & 12 \\
\hline & $B$ & f-imp & 13.7 & $\mathrm{P}$ & - & $\mathrm{P}$ & 10 \\
\hline \multirow{4}{*}{$\begin{array}{c}\text { Stepped } \\
\text { Gabion Weir }\end{array}$} & $G W$ & 0 & 15.4 & A & $\mathrm{A}$ & - & 3 \\
\hline & $G W$ & $i m p$ & 15.4 & A & $\mathrm{P}$ & - & 10 \\
\hline & $G W$ & $f$ & 15.4 & $\mathrm{P}$ & A & $\mathrm{A}$ & 11 \\
\hline & $G W$ & $f$-imp & 15.4 & $\mathrm{P}$ & $\mathrm{P}$ & $\mathrm{P}$ & 10 \\
\hline
\end{tabular}

Different hydraulic conditions were tested. The downstream water level ho was regulated using a gate and the discharge $Q$ varied between 4 1/s and 11 1/s. Experiments were also conducted in the same geometric conditions and configuration, for a constant discharge, but varying the downstream water level. For the present experiments, $h_{0} / H$ ranged between 0.25 and 0.82 .

Before starting each test, the channel bed was carefully leveled. Water was supplied using a re-circulating circuit. Preliminary tests, lasting up to 120 minutes, were conducted to establish the time to reach the equilibrium configuration and it was experimentally shown that after almost 40 minutes from the beginning of the test the equilibrium condition was reached. The water levels and the scour morphology were measured using a point gauge $0.1 \mathrm{~mm}$ precise. The hydraulic conditions and discharge range were selected in such a way that a dune always formed downstream of the scour hole.

The model scale was chosen according to Chinnarasri et al. (2009) and Pegram et al. (1999). In particular, Pegram et al. (1999) checked the sensitivity of water depths when the model scale ranged between 1:20 and 1:10 for stepped spillways modeling the same structure height $(30 \mathrm{~m})$ with the same step height $(0.5 \mathrm{~m})$. They concluded that models of 1:20 or larger scale could faithfully represent the prototype behaviour of stepped weirs. The model scale used for the present experiments can be considered at least 1:20, as, in practical applications, gabion weir step height 
and length are generally less than $1 \mathrm{~m}$. The same considerations can be done for rock grade control structures.

\section{RESULTS AND DISCUSSION}

\subsection{Flow characteristics}

The classification of the flow regimes is similar for both rock grade control structures and stepped gabion weirs. It has to be noted that these are peculiar structures, thus the classification can be done by only considering the flow pattern similarities occurring on stepped spillways and the analyzed structures. Figure 3 a-c shows pictures illustrating the three different regimes occurring on the stepped gabion weirs.

Namely, in Fig. 3a, it can be observed that a Nappe Flow regime occurs as the flow plunges on the successive steps and the dissipative process mainly takes place on the steps themselves. In Fig. 3c, the flow appears coherent and streams on a pseudo bottom. A close observation of the phenomenon shows that horizontal axial vortices re-circulating below the pseudo-bottom take place, thus the flow characteristics appear to be quite similar to those occurring in the stepped spillways in the presence of a Skimming Flow regime. The Transition Flow regime is illustrated in Fig. 3b. In this case, the jet does not impinge directly on the successive step, but at the same time, no coherent stream flow takes place on the structure, as the water surface appears very undular and horizontal axis vortices are not fully developed as in the case of Skimming Flow. The same qualitative flow structure behaviour was observed for rock grade control structure.
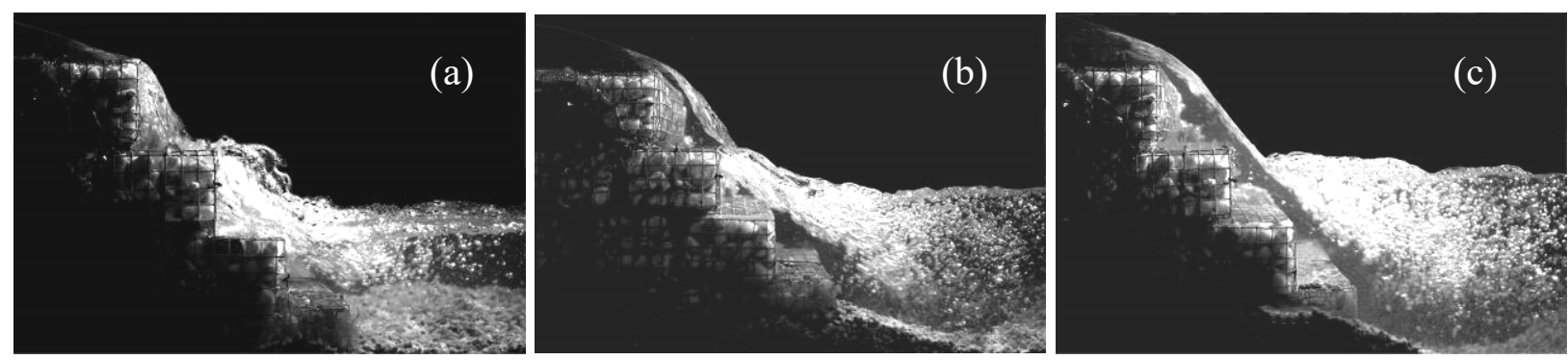

Figure 3 Flow characteristics on the structure $G W_{f}$ : (a) Nappe Flow $\left(A_{50}=0.55, h_{0} / H=0.31\right)$, (b) Transition Flow

$$
\left(A_{50}=0.62, h_{0} / H=0.67\right),(\mathrm{c}) \text { Skimming Flow }\left(A_{50}=0.78, h_{0} / H=0.60\right)
$$


The onset of Skimming Flow regime was deeply analyzed by several authors in the presence of stepped spillways. This topic assumes a particular importance in the case of both stepped gabion weirs and rock grade control structure because of the different scour processes that can occur downstream of the structure in the presence of a mobile bed. Moreover, in the previous studies (see for example Chanson 1994, Boes and Hager 2003, Ohtsu et al. 2004), the investigation of the flow conditions were conducted using impermeable stepped spillways and the structure was not partially submerged by the downstream flow.

In particular, Ohtsu et al. (2001) analyzed the hydraulic conditions for which each flow regime occurs on a stepped channel. They proposed a classification by which, knowing the hydraulic and geometric parameters, it is possible to foresee the flow regimes. They distinguished the various existence fields of the different flow conditions in a graph $h_{s} / k_{c}$ versus tan $\alpha$, where $h_{s}$ is the step height, $k_{c}$ the critical flow depth and $\tan \alpha$ is the channel slope. In the case of a stepped channel, whose slope is $45^{\circ}$, Ohtsu et al. (2001) showed that the Transition Flow region occurs for $h_{s} / k_{c}$ approximately ranging between 1 and 1.6.

The same classification was done in the present paper for both the tested structures. Considering that the structure slope is constant and equal to $45^{\circ}$, the other parameters which mainly influence the passage between the different regimes is the downstream flow depth and the upstream boundary and hydraulic conditions. The effect of downstream water level interferes with the flow regime on the structure, especially in the case of a permeable structure (i.e. gabion stepped weirs) as it modifies the infiltration regime through the structure itself. Also the presence of a filtration layer upstream of the structure, in the case in which no impermeable coverings are present, can influence the infiltration regime. Thus, for each series of experiments, the flow regime was analyzed and classified.

Data relative to each tested configuration were classified and reported in a graph $h_{s} / k_{c}$ versus $h_{0} / H$. Figure $4 \mathrm{a}$ shows the experimental data relative to the three regimes in the case of gabion stepped weirs. It can be observed that both the structure configuration and downstream tailwater 
level affect the transition between the various flow regimes. In particular, for the same low $h_{0} / H$ values, in the case of the permeable structure, the transition between Nappe and Skimming Flow occurs at lower $h_{s} / k_{c}$; with $h_{s}$ being constant, this means that the transition takes place at higher discharges. This is mainly due to the fact that at lower discharges, a significant infiltration takes place, thus a typical flow structure like that reported in Fig. 3a occurs. This phenomenon is more evident in the case of low $h_{0} / H$ values as, for high $h_{0} / H$ values, the infiltration mechanism through the structure varies, and a distinction between the flow regimes appears more evident.

However, a rough qualitative delimitation of the existence fields of the various regimes can be done in the tested ranges of parameters and extended to all structure configurations. In particular, from Fig. 4a, it can be easily inferred that the Nappe Flow regime occurs for $h_{s} / k_{c}$ values larger than 1.5, whereas Skimming Flow regime takes place for $h_{s} / k_{c}<1.1$. For $1.1<h_{s} / k_{c}<1.5$, mainly Transition Flow regime occurs, but, according to the different tested structure and especially for low $h_{0} / H$ values, the distinction appears less evident. It has to be noted that the range of existence of the Nappe Flow regime and Skimming Flow regime are very close to that proposed by Ohtsu et al. (2001) for stepped channels and for $\tan \alpha=1$.

The same analysis was also conducted in the presence of rock grade control structure, for the various tested configurations, considering $h_{s}=D_{50} / 2 \cong 3.5 \mathrm{~cm}$, as the stones partially protrude from the structure. In this case, it was observed that the flow characteristics on the structure are more homogeneous for the different tested configurations. In fact, a transition region occurs for all tested $h_{0} / H$ values, in the range $0.9<h_{s} / k_{c}<1.1$. Note that in this case, the structure is almost impermeable, as the rocks were linked using a silicon glue. Moreover, also the effect of downstream water level, such as the effect of different boundary configurations, is less prominent than the stepped gabion weir. In Figure $4 b$, the experimental data, relative to the different flow regimes in the presence of a rock grade control structure, are presented in a graph $h_{s} / k_{c}$ versus $h_{0} / H$. 

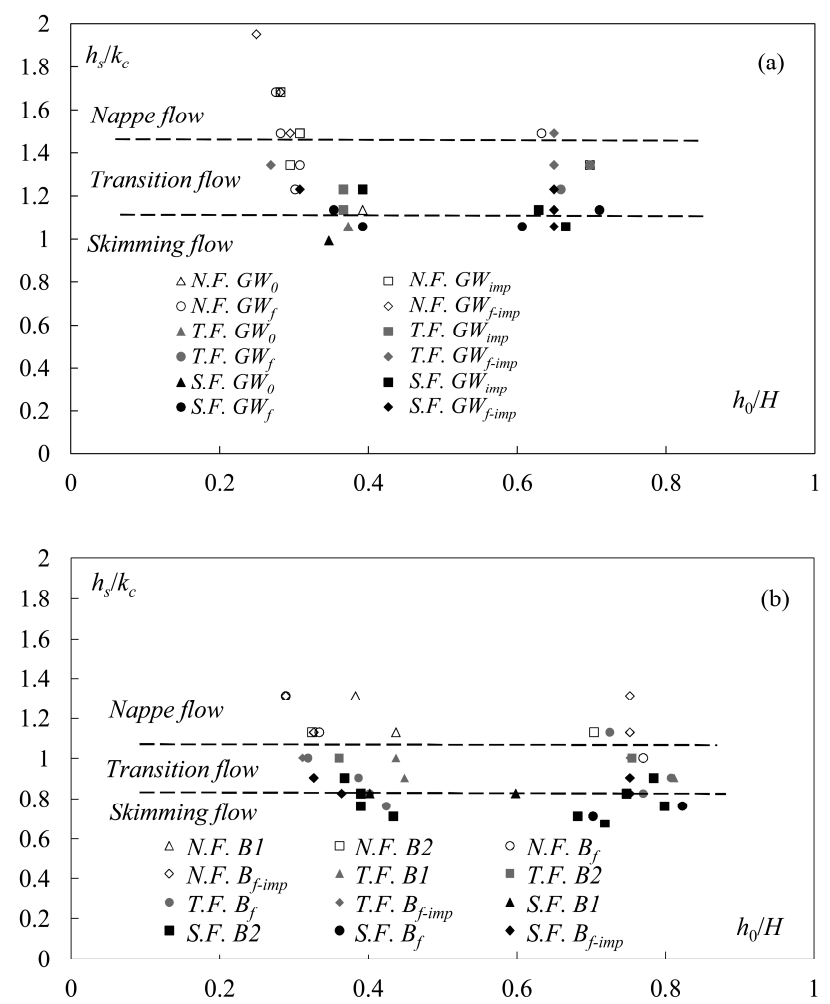

Figure 4 Flow regimes for (a) stepped gabion weirs and (b) grade control structures (note N.F.=Nappe Flow, T.F.=Transition Flow and S.F.=Skimming Flow)

\subsection{Hydraulic jump and sediment transport downstream of the structure}

The presence of a mobile channel bed deeply influences the flow pattern in the stilling basin. For each tested configuration and flow condition, the flow characteristics and the sediment transport direction were analyzed. Namely, when the scour hole equilibrium condition is reached, two main hydraulic jump typologies can be distinguished. The flow structure in the stilling basin appears similar to that described by Pagliara (2007) downstream of a block ramp, even though in the cited study the hydraulic jump never submerged the ramp toe, in contrast to the present study. Thus, in the present paper, primarily two different hydraulic jump typologies were distinguished and termed as in Pagliara (2007), namely $F_{M B}$ and $S_{M B}$.

$F_{M B}$ hydraulic jump type is characterized by a clock wise flow re-circulation and the sediment are transported both upstream and downstream (see Fig. 5a), whereas the hydraulic jump type $S_{M B}$ is 
characterized by a counter clock wise flow re-circulation and the sediment are transported only downstream (see Fig. 5b).
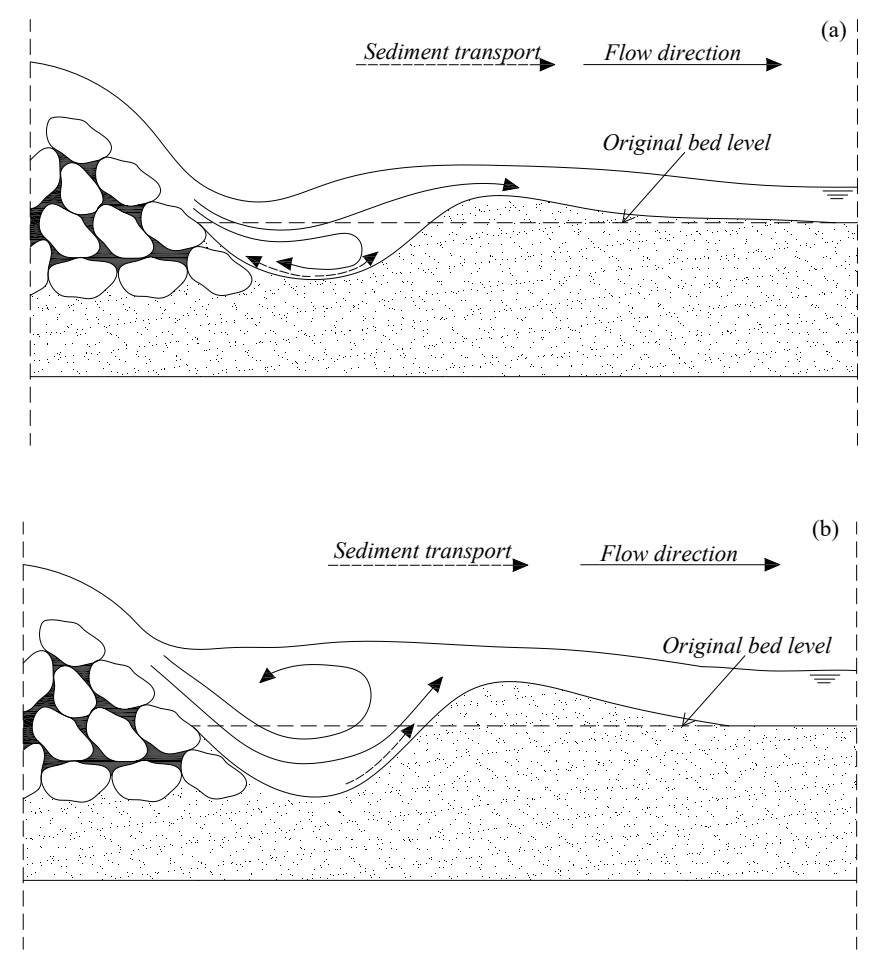

Figure 5 Diagram sketch of the flow pattern and sediment transport direction in the stilling basin: hydraulic jump (a)

$$
F_{M B} \text { and (b) } S_{M B}
$$

Figure 6 illustrates the existence fields of the two hydraulic jumps for the various tested configurations and different flow conditions in a diagram $h_{0} / H$ versus $A 50=q /\left[H \cdot\left[g \cdot d_{50} \cdot(\Delta \rho / \rho)\right]^{0.5}\right]$, in which the parameter $A_{50}$ was introduced by D'Agostino and Ferro (2004), where $q$ is the unit discharge, $g$ is the acceleration due to gravity, $\Delta \rho=\rho_{s^{-}} \rho$, where $\rho_{s}$ is the sediment density and $\rho$ the water density. This non dimensional parameter takes into consideration both the geometric and hydraulic characteristics, including the sediment size of the stilling basin.

It can be noted that the main parameter affecting the hydraulic jump type is the downstream water level. In fact, for all the tested structure configurations and discharges, the main distinction can be done based on the relative downstream tailwater level. The increase of the downstream water level forces the hydraulic jump to occur close to the structure toe or on the structure itself. A rough qualitative classification, reported in the Fig. 6 , shows that for $h_{0} / H>0.5$ there is a clear distinction between the two typologies. The hatched region indicates the transition between the two typologies. 


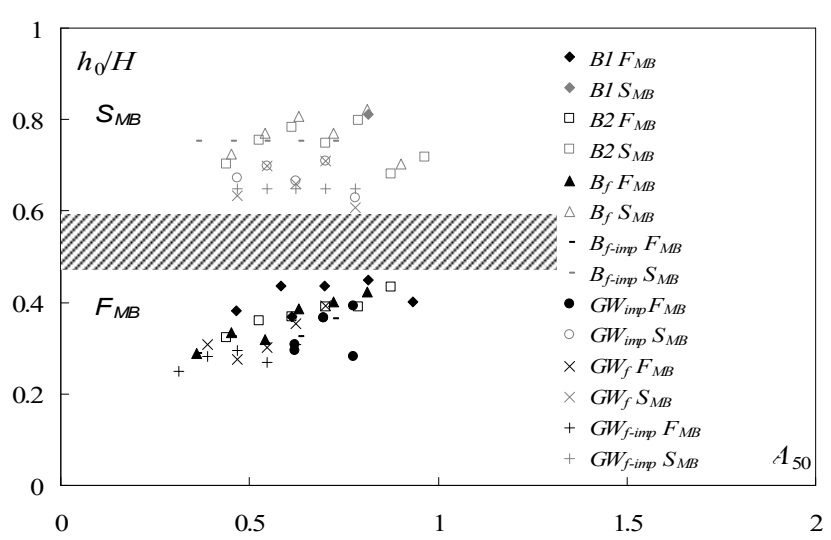

Figure 6 Existence field of the two hydraulic jumps typologies

\subsection{Scour hole estimation}

\subsubsection{Scour hole depth}

In terms of practical applications, experimental formulae, by which one can evaluate the main geometric lengths of the scour hole, are very useful. In particular, the most important parameter that has to be evaluated is the scour hole depth. A preliminary analysis based on experimental data and on the studies conducted by D'Agostino and Ferro (2004) allowed to establish that, for each type of structure configuration tested, the scour hole depth mainly depends on the following parameters:

$$
z_{\max }=f\left(q, h_{0}, \Delta \rho, \rho, d_{50}, g, H, E_{0}\right)
$$

in which $E_{0}$ is the total energy head upstream of the structure. In Eq. (1), structure permeability, sediment non-uniformity and structure configurations were not taken into consideration, as one uniform channel bed material was used, and Eq. (1) is related to each type of structure configuration tested.

According to D'Agostino and Ferro (2004), the non-dimensional parameter $A_{50}$ was introduced and used to determine an experimental relationship in order to predict the maximum scour hole depth. Thus, it was experimentally shown that, for each structure configuration, the following non dimensional relationship can be obtained and, for practical purposes, satisfactorily predicts the experimental data: 


$$
\frac{z_{\max }}{E_{0}}=f\left(A_{50}, h_{0} / H\right)
$$

The parameter $A_{50}$, termed as dimensionless group associated to grain size $d_{50}$ by D'Agostino and Ferro (2004), takes into consideration both the granulometric and hydraulic characteristics. The analysis was conducted separately for each type of structure and for each configuration tested. Namely, the data were plotted in a graph $z_{\max } / E_{0}$ versus $A_{50}$ and grouped for each selected range of the parameter $h_{0} / H$. Three different $h_{0} / H$ ranges were distinguished, i.e. $0<h_{0} / H<0.33$, $0.33<h_{0} / H<0.67, h_{0} / H>0.67$. Moreover, the data were also grouped considering the flow regime occurring on the structure. This analysis showed that the general behaviour mainly and significantly depends on the flow regime.

For rock grade control structures, the data are reported in Figure 7 a-c, relative to the different structure boundary conditions (i.e. $B 1-B 2$ in Fig. 7 a, $B_{f}$ in Fig. $7 \mathrm{~b}$ and $B_{f-i m p}$ in Fig. 7 c). A different behaviour in terms of maximum scour depth according to the flow regimes can be noted. Namely, the slope of the curve chosen to interpolate the experimental data increases passing from Nappe Flow to Skimming Flow regime. The transition between the two different trends, irrespective of the relative submergence $h_{0} / H$, generally occurs for $0.5<A_{50}<0.7$. Another important observation that has to be pointed out is that the general behaviour varies according to the different structure configurations tested. Namely, with being $A_{50}$ constant, the ratio $z_{\max } / E_{0}$, increases passing from structures $B 1-B 2$ to $B_{f-i m p}$.

To furnish a simple tool in order to estimate the maximum scour depth, the experimental data were interpolated and the following three different equations were derived for the different structure configurations tested, which are valid in the tested range of hydraulic and geometric parameters. Note that the following equations do not take into account the effect of the parameter $h_{0} / H$. This occurrence does not mean that $h_{0} / H$ is not influencing the phenomenon, but for practical purposes, its effect can not be considered, as the following equations, depending only on $A 50$, are able to 
satisfactorily predict all data. In addition, it has to be noted that the effect of $h_{0} / H$ is not clearly detectable. In fact, no unique and clear trend can be established.

$\frac{z_{\max }}{E_{0}}=3.28 A_{50}^{3}-6.28 A_{50}^{2}+4.74 A_{50}-0.95$

valid for $B 1-B 2\left(R^{2}=0.86\right)$

$\frac{z_{\max }}{E_{0}}=3.46 A_{50}^{3}-6.96 A_{50}^{2}+5.42 A_{50}-1.09$

valid for $B_{f}\left(R^{2}=0.74\right)$

$\frac{z_{\max }}{E_{0}}=13.46 A_{50}^{3}-22.02 A_{50}^{2}+13.12 A_{50}-2.32$

valid for $B_{f-\text { imp }}\left(R^{2}=0.76\right)$
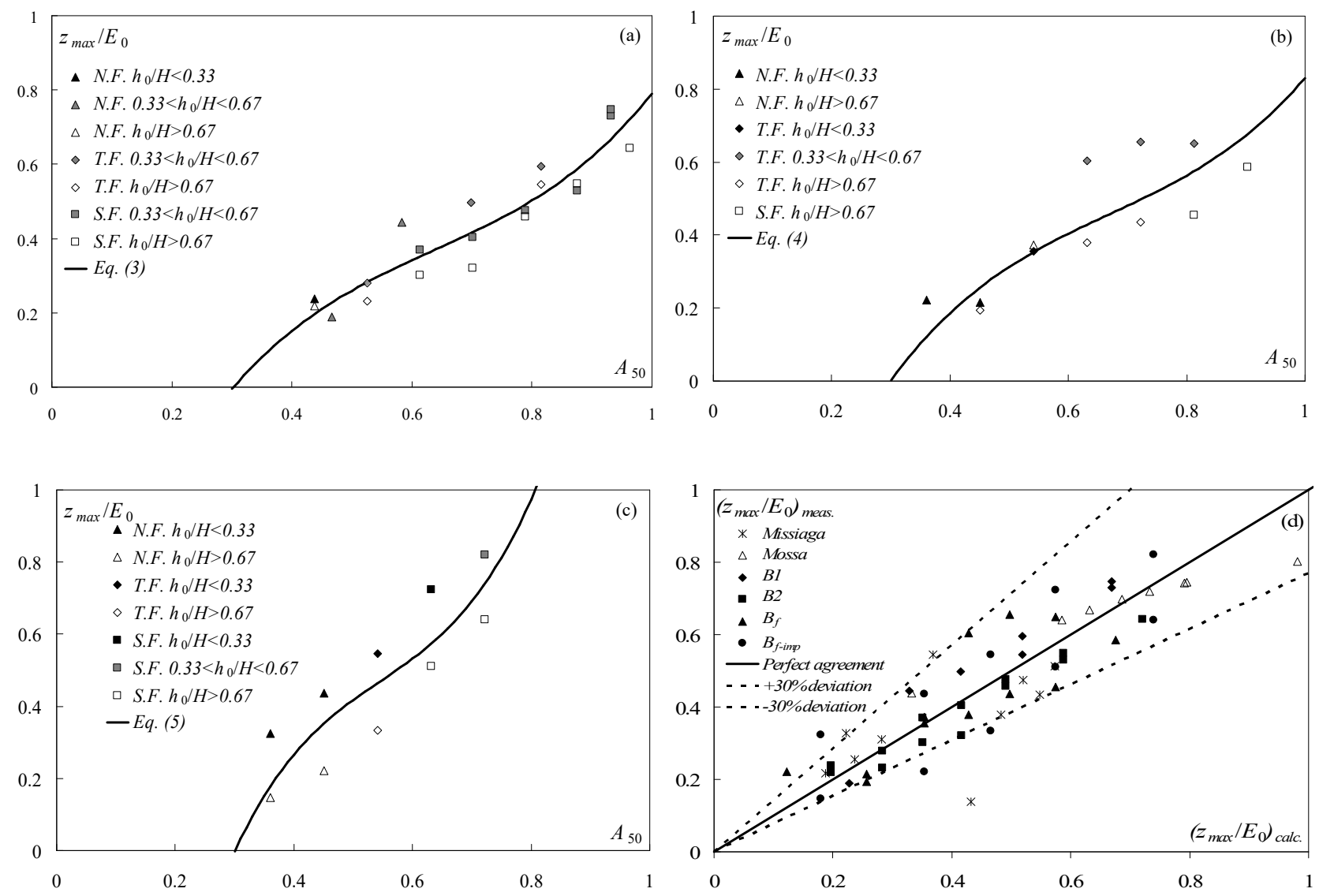

Figure $7\left[z_{\max } / E_{0}\right]\left(A_{50}\right)$ for rock grade control structure (a) $B 1-B 2$, (b) $B_{f}$, (c) $B_{f-i m p}$ with the indication of different flow regimes (i.e. S.F.=Skimming Flow, T.F.=Transition Flow, N.F.=Nappe Flow) and relative submergence $h_{0} / H$; (d) comparison between measured and calculated values of the variable $z_{\max } / E_{0}$. 
The previous equations are plotted in Figure $7 \mathrm{a}-\mathrm{c}$, respectively, along with the experimental data. Figure $7 \mathrm{~d}$ shows the comparison between measured and calculated values of the variable $z_{\max } / E_{0}$ for the different structure configurations tested, along with the estimated value of $z_{\max } / E_{0}$ of data derived from Mossa (1998), relative to a grade control structure whose downstream face slope varied between $18^{\circ}$ and $45^{\circ}$, and other data collected in Missiaga stream (Belluno, Italy) and reported in D'Agostino and Ferro (2004).

The same analysis was conducted for three of the different stepped gabion weirs, namely for the structure configurations $G W_{i m p}, G W_{f}, \mathrm{GW}_{f-i m p}$. The analysis of the experimental data shows that also in this case, there is a general behaviour which is similar to the rock grade control structure. Likewise, a transition between two different scour behaviours can be pointed out. The transition occurs in the same $A_{50}$ range as above.

Despite to the previous case, the three different structure configurations do not affect the trend significantly. It means that, for practical purposes, one average trend can represent all experimental data. Thus, one unique interpolating curve was chosen and adopted in order to furnish a simple tool to estimate the ratio $z_{\max } / E_{0}$. The following equation is proposed $\left(R^{2}=0.75\right)$

$$
\frac{z_{\max }}{E_{0}}=7.53 A_{50}^{3}-11.53 A_{50}^{2}+6.66 A_{50}-1.16
$$

In Figure 8a-d, the experimental data are reported. In particular, Figure 8a shows the data relative to the structure configuration $G W_{\text {imp }}$, Fig. $8 \mathrm{~b}$ is relative to $G W_{f}$ and Fig. $8 \mathrm{c}$ to $G W_{f-\text { imp }}$. In Figure $8 \mathrm{~d}$, all experimental data are reported along with the Eq. (6). Figure 9 shows the good agreement between the measured and calculated (using Eq. 6) data of the variable $z_{\max } / E_{0}$. 

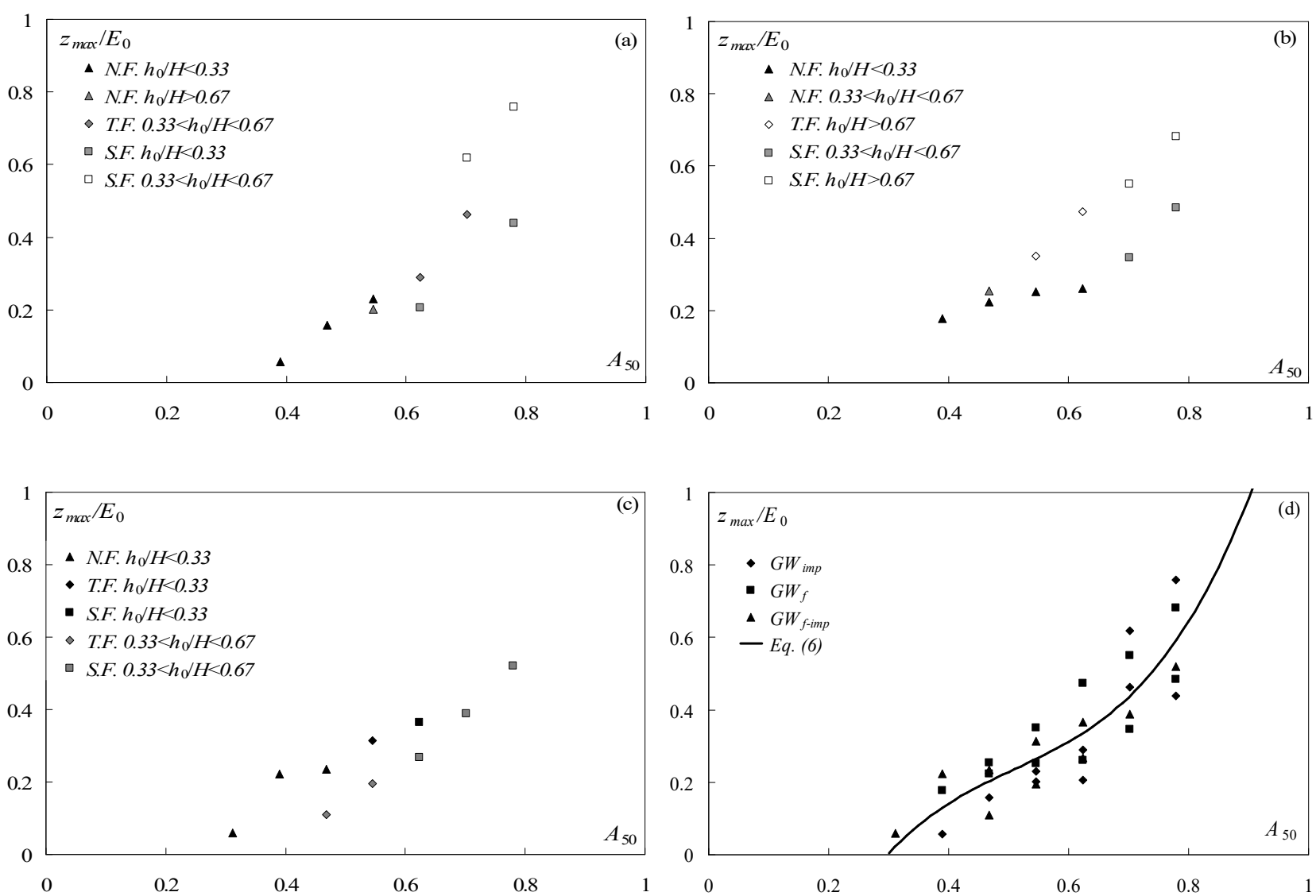

Figure $8\left[z_{\max } / E_{0}\right]\left(A_{50}\right)$ for stepped gabion weirs (a) $G W_{i m p}$, (b) $G W_{f}$, (c) $G W_{f-i m p}$ with the indication of different flow regimes (i.e. S.F.=Skimming Flow, T.F.=Transition Flow, N.F. $=$ Nappe Flow) and relative submergence $h_{0} / H$; $(\mathrm{d})$ plot of Eq. (6) along with all the experimental data.

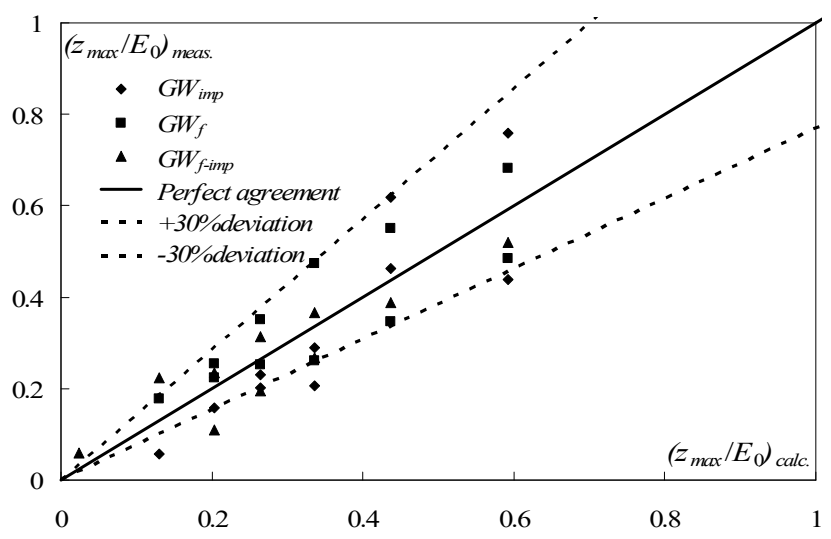

Figure 9 Comparison between measured and calculated values (using Eq. 6) of the variable $z_{\max } / E_{0}$

Experimental tests showed that the scour hole shape is not bi-dimensional, but a certain threedimensionality, especially for low values of the discharge (i.e. low $A 50$ ), can be pointed out. This occurrence can be partially due to the wall effect and it is a typical phenomenon occurring 
downstream of several hydraulic structures. Pagliara (2007) has already observed this phenomenon in the presence of block ramps finding the same decreasing trend of the ratio $z_{m a x} / z_{m}$ with discharge.

Thus another important parameter that can be considered in the scour analysis is the ratio between the maximum scour hole depth $z_{\max }$ and the average scour hole depth $z_{m}$ in the transversal section in which the maximum scour depth takes place. Namely, it was observed that for each hydraulic and structure configuration tested, the ratio $z_{\max } / z_{m}$ is a monotonic decreasing function of the parameter $A_{50}$. Figure 10a-b shows the plot $z_{\max } / z_{m}\left(A_{50}\right)$ for rock grade control structures and stepped gabion weirs. The experimental data, relative to all hydraulic conditions and structure configurations, were plotted and one unique average trend was identified, for both the structural typologies tested.
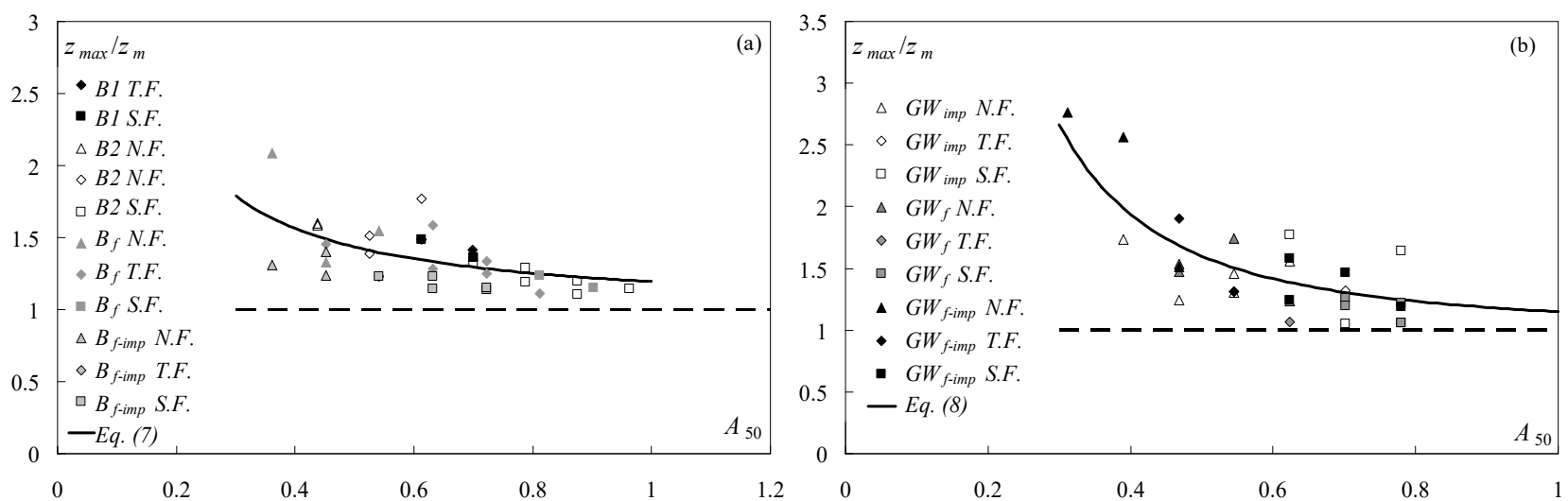

Figure $10 z_{\max } / z_{m}\left(A_{50}\right)$ for (a) rock grade control structure and for (b) stepped gabion weirs along with Eqs. (7) and (8), respectively

The two interpolating curves relative to rock grade control structures and stepped gabion weirs, respectively, are the following:

$$
\frac{z_{\max }}{z_{m}}=1+0.19 A_{50}^{-1.16}
$$

valid for rock grade control structures $\left(R^{2}=0.65\right)$, and

$$
\frac{z_{\max }}{z_{m}}=1+0.15 A_{50}^{-2}
$$

valid for stepped gabion weirs $\left(R^{2}=0.68\right)$. 


\subsubsection{Scour hole length}

Another important parameter that has to be taken into account for practical purposes is the scour hole length $l_{s}$. According to Breusers and Raudikivi (1991), the maximum scour length $l_{s}$ can be expressed as a function of the maximum scour depth $z_{\max }$. It was experimentally shown that this assumption is still valid for both the tested structural typologies. The non dimensional scour length $l_{s} / E_{0}$ was plotted in a graph $l_{s} / E_{0}\left(z_{\max } / E_{0}\right)$, for all the tested hydraulic conditions and structure configurations. For both the structure typologies, it was shown that there is a linear increase of $l_{s} / E_{0}$ with $z_{\max } / E_{0}$. Namely, as shown in Figure 11 for rock grade control structures, one unique average trend can be pointed out even if slight differences can be distinguished. But for practical purposes, the relationship between $l_{s} / E_{0}$ and $z_{\max } / E_{0}$ can be expressed by the following interpolating line, which was chosen passing through the axes origin (i.e. $l_{s}=0$ for $z_{\max }=0$ ):

$$
\frac{l_{s}}{E_{0}}=3.16 \frac{z_{\max }}{E_{0}}
$$

The proposed equation satisfactorily predicts all data $\left(R^{2}=0.82\right)$.

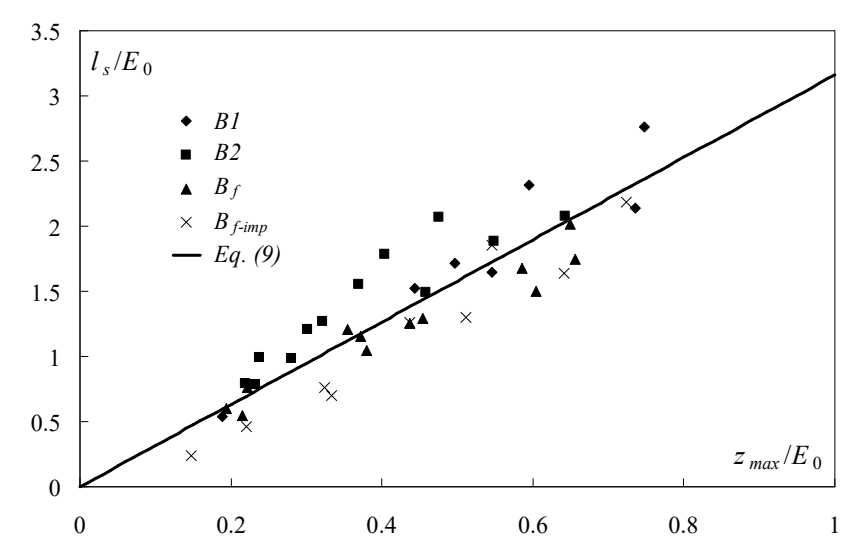

Figure $11\left[l_{s} / E_{0}\right]\left(A_{50}\right)$ for rock grade control structure $B 1-B 2, B_{f}$, and $B_{f-i m p}$

The same analysis was conducted for the case of stepped gabion weirs. In this case, a distinction has to be made between the different boundary configurations tested. In fact, the analysis of the experimental data shows that the slope of the interpolating lines changes slightly according to which structure configuration is considered. In particular, for impermeable structures, the interpolating line slope is higher. The following equations $10-12$ are proposed in order to evaluate $l_{s} / E_{0}$ 
$\frac{l_{s}}{E_{0}}=4.2 \frac{z_{\max }}{E_{0}}$

valid for stepped gabion weir $G W_{\text {imp }}\left(R^{2}=0.8\right)$

$\frac{l_{s}}{E_{0}}=3.6 \frac{z_{\max }}{E_{0}}$

valid for stepped gabion weir $G W_{f}\left(R^{2}=0.95\right)$

$\frac{l_{s}}{E_{0}}=5.1 \frac{z_{\max }}{E_{0}}$

valid for stepped gabion weir $G W_{f-i m p}\left(R^{2}=0.83\right)$

Figure $12 \mathrm{a}$-c reports the graphs $l_{s} / E_{0}\left(z_{\max } / E_{0}\right)$ for $G W_{i m p}, G W_{f}, G W_{f-i m p}$, respectively. Note that the different flow regimes occurring on the structure do not seem to significantly influence the relationship between the maximum scour depth and length. The same observation can be made for the hydraulic conditions (i.e. $\left.h_{0} / H\right)$.
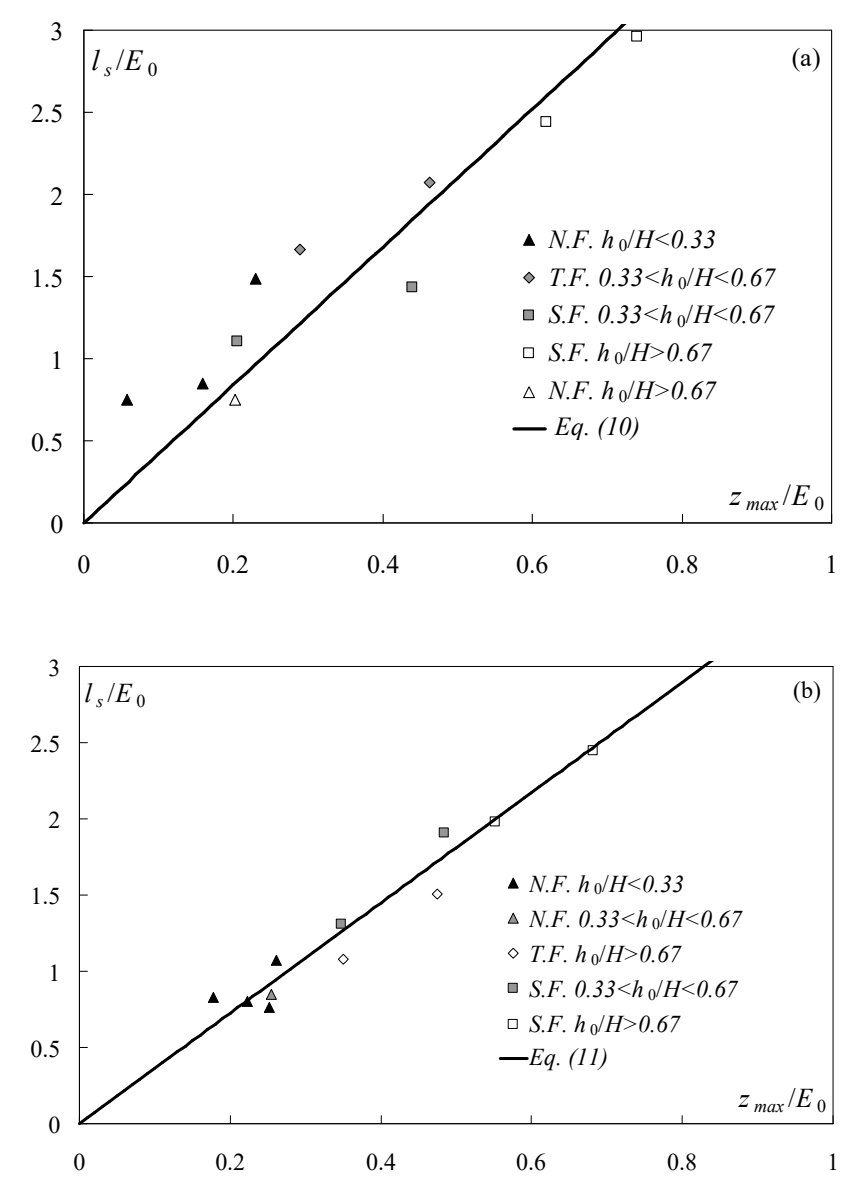


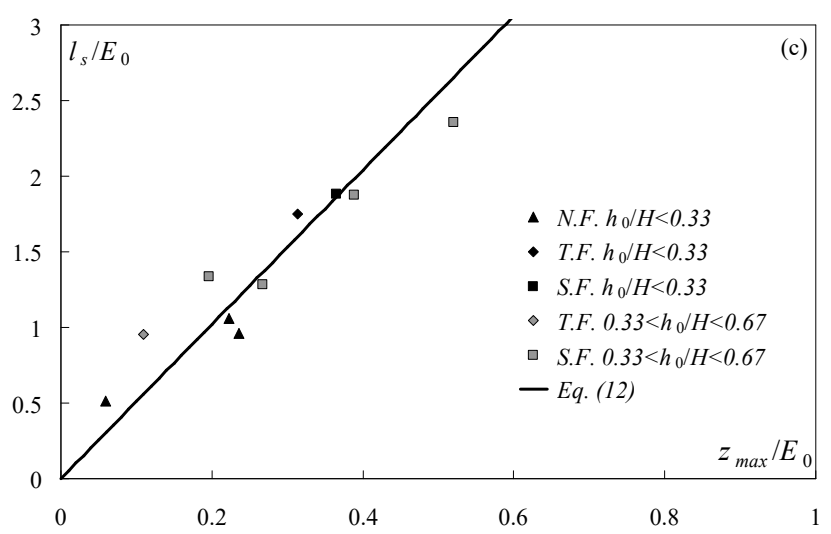

Figure 12 (a) $\left[l_{s} / E_{0}\right]\left(A_{50}\right.$ ) for stepped gabion weir (a) $G W_{i m p}$, (b) $G W_{f}$, and (c) $G W_{f-i m p}$

\subsubsection{Dune height}

The dune downstream of the scour hole assumes a fundamental role in the scour process, as it constitutes a limiting factor for the scour process evolution and at the same time contributes to either force or confine the hydraulic jump. In the present paragraph, just a qualitative behaviour of the dune evolution in terms of maximum height $z_{M}$ is furnished, according to the different hydraulic conditions. Namely, for each structure boundary condition and by varying the hydraulic parameters, the dune height was analyzed. In the following Fig. 13a-b, the non dimensional dune height $Z_{M}=z_{M} / E_{0}$ is analyzed for two boundary structure conditions, but the general qualitative behaviour is practically the same for all the tested configurations.

Figure 13a reports a graph $Z_{M}\left(A_{50}\right)$ for structure $B_{f-i m p}$, whereas Figure $13 \mathrm{~b}$ reports the same for structure $G W_{f}$. From these figures it can be deduced that the non dimensional height has the same qualitative behaviour, i.e. varying the downstream water depth, but being constant $A_{50}, Z_{M}$ increases for high relative tailwater. This occurrence can be easily explained considering that by increasing tailwater, the shear stresses are reduced, thus the dune height is higher. Moreover, the pseudo-parabolic trend of experimental data increasing $A_{50}$ is due to the fact that, up to a certain discharge, the scour hole increases and as does the dune height, whereas increasing the discharge the hydraulic jump shifts downstream and the dune becomes flatter. According to the proposed classification of the flow regime, it can be observed that the maximum non dimensional dune height 
generally occurs in correspondence with the transition between Nappe Flow and Skimming Flow regimes. The effect of the increase of the parameter $h_{0} / H$ is to shift the trend of the experimental data towards higher $Z_{M}$ values for the reason illustrated above.
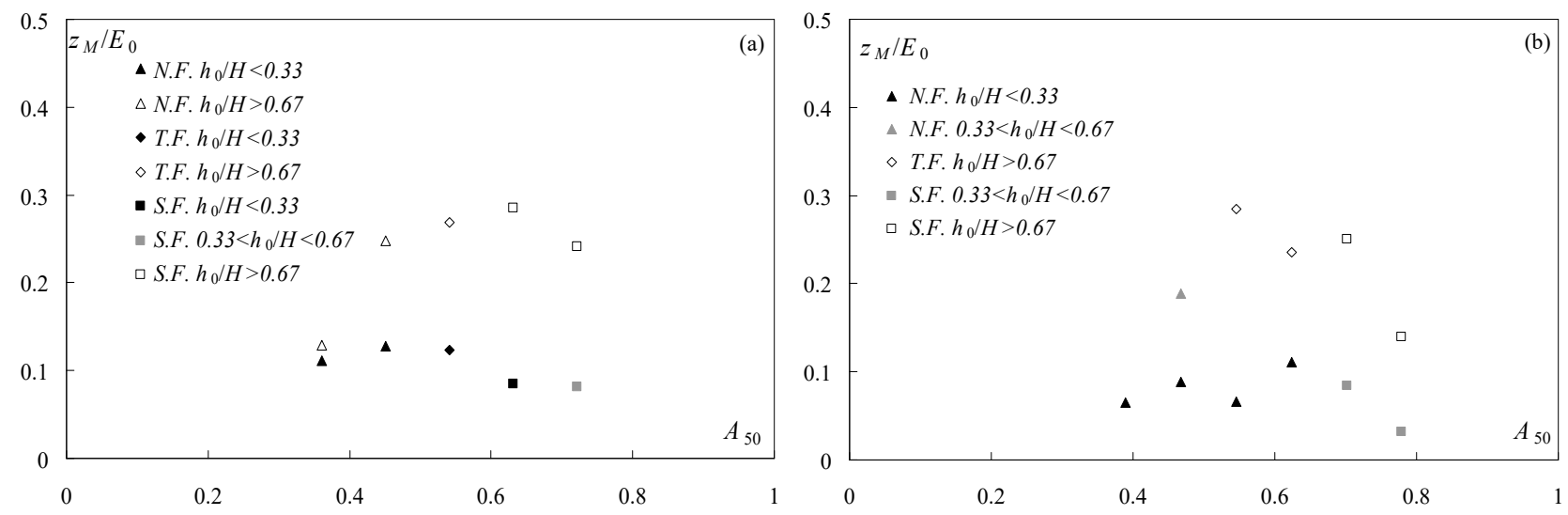

Figure 13 (a) $\left[z_{M} / E_{0}\right]\left(A_{50}\right)$ for (a) rock grade control structure $B_{f-\text { imp }}$ and (b) for stepped gabion weir $G W_{f}$.

\subsubsection{Non dimensional profiles}

The analysis of the scour features also includes the non dimensional scour hole profiles, as function of $X=x / l_{s}$, the non dimensional longitudinal coordinate, and $Z=z / z_{\max }$, the non dimensional vertical coordinate, where $x$ and $z$ are the longitudinal and vertical axes, respectively, as reported in Figures $1 a-b$ and $2 a-b$.

Once the equilibrium configuration was reached, the whole axial profile was measured in selected transversal sections and was made non dimensional as specified. Data analysis showed that there is a similitude between non dimensional profiles in the presence of the same structure typology, as shown in Figure $14 \mathrm{a}-\mathrm{b}$ for all tested rock grade control structures and stepped gabion weirs, respectively. Thus, for practical purposes, one unique non dimensional profile was found for rock grade control structures and stepped gabion weirs.

It was observed that the maximum depth, in the case of rock grade control structure, commonly occurs at $X \sim 0.5$ (see Fig. 14a). Whereas for stepped gabion weirs, the maximum scour depth generally occurs for $X \sim 0.35-0.4$ (see Fig. 14b). This behaviour can be explained considering that the rock grade control structure is practically impermeable, whereas the stepped gabion weir 
allows water infiltration. Thus, in this last case, the hydraulic jump generally occurs closer to the structure. Two empirical equations are also proposed in order to evaluate the non dimensional profiles for both the structural typologies:

$Z=1.38 X^{3}-6.05 X^{2}+4.66 X$

valid for rock grade control structures, and

$Z=4.36 X^{3}-10.27 X^{2}+5.9 X$

valid for stepped gabion weirs.

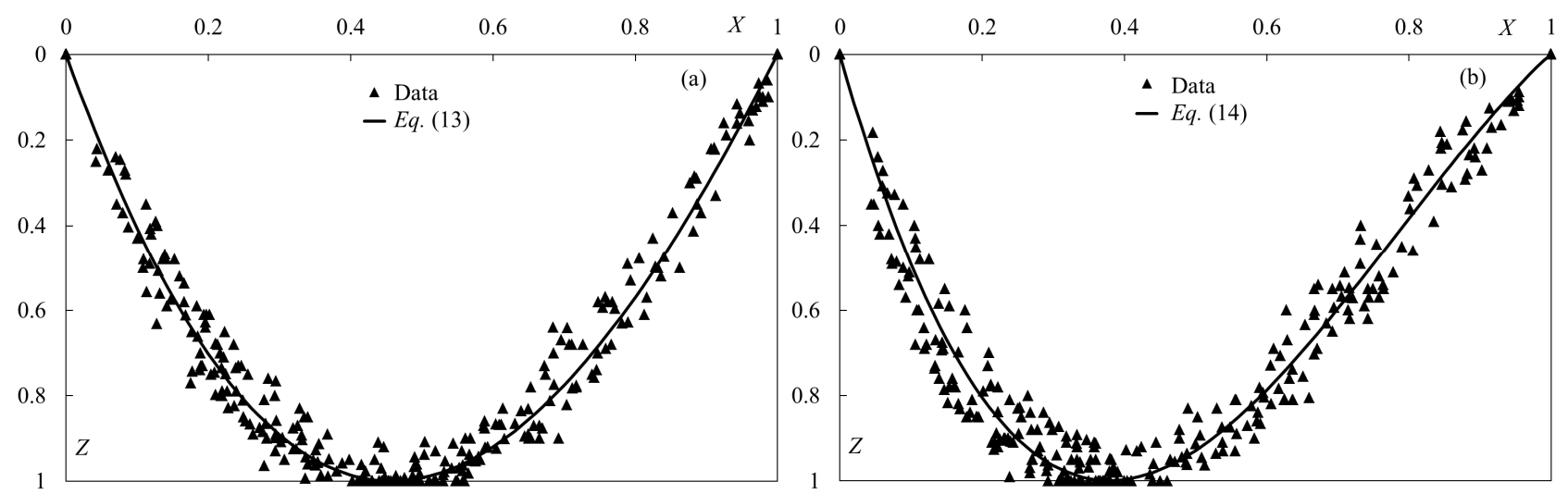

Figure 14 Non dimensional profiles for (a) rock grade control structures along with Eq. (13) and for (b) stepped gabion weirs along with Eq. (14)

\section{CONCLUSIONS}

In the present study, an analysis of the scour process and flow patterns downstream of both rock grade control structures and stepped gabion weirs is performed. The flow behaviour on the structures itself is also analysed. Experimental tests were conducted in different structure boundary conditions, for various relative submergences and inflow discharges. It was primarily observed that three different flow behaviours on the structures take place: Nappe Flow, Transition Flow and Skimming Flow. They were classified as those occurring on stepped spillways, as they show substantial similarities with them, even if in the present study the structures are appreciably different. A qualitative classification was proposed by which it is possible to foresee the flow regimes which will occur, knowing the structure boundary conditions and hydraulic parameters, 
namely $h_{s} / k_{c}$ and $h_{0} / H$. In particular, it was observed that the classification appears similar to that proposed by Ohtsu et al. (2001).

Also the flow pattern downstream of the structures was analysed. The analysis was focused on the hydraulic jump types and sediment transport directions. Two different hydraulic jump types were distinguished and classified: $F_{M B}$ and $S_{M B}$. According to the different hydraulic jump types, two different flow circulations and sediment transport directions take place. It was observed that a clear distinction between the two hydraulic jumps can be made for $h_{0} / H>0.5$, for each structure and boundary condition tested.

Finally, an analysis of the scour mechanism and of the main lengths of the scour hole were performed. It was observed that the flow regime occurring on the structures deeply influences the scour process, especially in terms of maximum scour depth, which increases much more rapidly when a Skimming Flow regime takes place. Simple empirical relationships are proposed in order to foresee the main lengths, i.e. maximum scour depth, maximum axial length and non dimensional axial profiles.

A comparison between the rock grade control structures and stepped gabion weirs in terms of maximum scour depth, shows that for the same hydraulic conditions, there are slight differences in terms of the non dimensional scour depths. It means that for practical purposes, the scour depths of structures $G W_{i m p}, G W_{f}, G W_{f-i m p}$ are comparable with those occurring with structures $B 1-B 2$ and $B f$. For structure $B_{f-i m p}$, the scour depth is higher, $A 50$ being constant. This is mainly due to the fact that, when no infiltration occurs in the upstream layer and the structure itself is impermeable, the energy is mainly dissipated on the structure itself and in the scour process.

From a practical point of view, especially in rivers in which cohesive materials are present, it means that a stepped gabion weir is preferred in terms of maximum scour depth reduction. In fact, when the upstream part of the structure is filled with the cohesive river material, it behaves as a structure with an impermeable filtering layer upstream. Yet it has to be considered that rock grade control structures are much more environmental friendly, as they have a reduced environmental 
impact. Thus, a correct process of design has to take into consideration several aspects, including those not strictly technical. 


\section{NOTATION}

$A_{50}=q /\left[H \cdot\left[g \cdot d_{50} \cdot(\Delta \rho / \rho)\right]^{0.5}\right]$ non dimensional group.

$D_{50}=$ average diameter of rock grade control structure material, [L].

$d_{x x}=$ diameter of the channel bed and filtering layer material for which $\mathrm{xx} \%$ of sediment is finer,

[L].

$d_{50}=$ diameter of the channel bed material and filtering layer for which $50 \%$ of sediment is finer, [L].

$d_{90}=$ diameter of the channel bed material and filtering layer for which $90 \%$ of sediment is finer,

[L].

$E_{0}=$ total energy head upstream of the structure, [L].

$f=$ function of.

$g=$ gravitational acceleration, $\left[\mathrm{LT}^{-2}\right]$.

$h_{0}=$ tailwater level, [L].

$h=$ water depth measured from the horizontal plane passing through the top structure, [L].

$h_{s}=$ height of the steps, [L].

$H=$ structure height, [L].

$k_{c}=$ critical depth, [L].

$l_{s}=$ axial scour hole length, $[\mathrm{L}]$.

$Q=$ water discharge, $\left[\mathrm{L}^{3} \mathrm{~T}^{-1}\right]$.

$q=$ unit discharge, $\left[\mathrm{L}^{2} \mathrm{~T}^{-1}\right]$.

$w_{s}=$ length of the steps, [L].

$x=$ longitudinal coordinate, $[\mathrm{L}]$.

$X=x / l_{s}=$ non dimensional longitudinal coordinate

$z=$ vertical coordinate, $[\mathrm{L}]$.

$z_{\max }=$ maximum scour hole depth, $[\mathrm{L}]$. 
$z_{m}=$ average scour hole depth in the transversal section in which the maximum scour hole depth takes place, [L].

$z_{M}=$ dune height, [L].

$Z=z / z_{\max }=$ non-dimensional vertical coordinate.

$\Delta \rho=\left(\rho_{s}-\rho\right)$ reduced sediment density, $\left[\mathrm{ML}^{-3}\right]$.

$\rho_{s, \rho}=$ sediment density and water density, $\left[\mathrm{ML}^{-3}\right]$.

$\sigma=\left(d_{84} / d_{16}\right)^{0.5}=$ sediment non uniformity parameter. 


\section{REFERENCES}

Boes, R.M., and W.H. Hager (2003), Hydraulic design of stepped spillways, Journal of Hydraulic Engineering 129(9), 671-679.

Bormann, N.E., and P.Y. Julien (1991), Scour Downstream of Grade-Control Structures, Journal of Hydraulic Engineering 117(5), 579-594.

Bremen, B., and W.H. Hager (1993), T-jump in abruptly expanding channel, Journal of Hydraulic Research 31(1), 61-78.

Breusers, H.N.C., and A.J. Raudkivi (1991), Scouring, Balkema, Rotterdam NL.

Chanson, H. (1994), Hydraulics of skimming flows over stepped channels and spillways, Journal of Hydraulic Research 32(3), 445-460.

Chanson, H. (1996), Prediction of the transition nappe/skimming flow on a stepped channel, Journal of Hydraulic Research 34(3), 421-429.

Chinnarasri, C., Donjadee, S., and U. Israngkura (2008), Hydraulic characteristics of gabionstepped weirs, Journal of Hydraulic Engineering 134(8), 1147-1152.

D'Agostino, V., and V. Ferro (2004), Scour on alluvial bed downstream of grade-control structures. Journal of Hydraulic Engineering 130(1), 24-37.

Dey, S., and R.V. Raikar (2005), Scour in long contractions, Journal of Hydraulic Engineering 131(12), 1036-1049.

Dey, S., and R.V. Raikar (2007), Scour below a high vertical drop, Journal of Hydraulic Engineering 133(5), 564-568.

Dey, S., and A. Sarkar (2006a), Scour downstream of an apron due to submerged horizontal jets, Journal of Hydraulic Engineering 132(3), 246-257.

Dey, S., and A. Sarkar (2006b), Response of velocity and turbulence in submerged wall jets to abrupt changes from smooth to rough beds and its application to scour downstream of an apron, Journal of Fluid Mechanics 556, 387-419. 
Dey, S., and A. Sarkar (2008), Characteristics of submerged jets in evolving scour hole downstream of an apron, Journal of Engineering Mechanics 134(11), 927-936.

Dey, S., and B. Westrich (2003), Hydraulics of submerged jet subject to change in cohesive bed geometry, Journal of Hydraulic Engineering 129(1), 44-53.

Essery, I.T.S., and M.W. Horner (1978), The hydraulic design of stepped spillways, CIRIA, Report $n^{\circ} 33,3^{\text {rd }}$ Edition, Jan, London, UK.

Hoffmans, G.J.C.M., and H.J. Verheij (1997), Scour manual, Balkema, Rotterdam NL.

Mohamed, H.I. (2010), Flow over gabion weirs, Journal of Irrigation and Drainage Engineering 136(8), 573-577.

Mossa, M. (1998), Experimental study on the scour downstream of grade-control structures, Proceedings $26^{\text {th }}$ Convegno di Idraulica e Costruzioni Idrauliche, Catania, Italy, September $3,581-594$.

Ohtsu, I., Yasuda, Y., and M. Takahashi (2000), Discussion of "Hydraulics of skimming flow on modeled stepped spillways" by Pegram, G.G.S, Officer, A.K, and S.R. Mottram, Journal of Hydraulic Engineering 126(12), 950-951.

Ohtsu, I., Yasuda, Y., and M. Takahashi (2001), Discussion of "Onset of skimming flow on stepped spillways" by Chamani, M.R., and N. Rajaratnam, Journal of Hydraulic Engineering 127(6), 522-524.

Ohtsu, I., Yasuda, Y., and M. Takahashi (2004), Flow characteristics of skimming flows in stepped channels, Journal of Hydraulic Engineering 130(9), 860-869.

Pagliara, S. (2007), Influence of sediment gradation on scour downstream of block ramps, Journal of Hydraulic Engineering 133(11), 1241-1248.

Pagliara, S. and P. Chiavaccini (2006), Energy dissipation on reinforced block ramps, Journal of Irrigation and Drainage Engineering 132(3), 293-297.

Pagliara, S., and M. Palermo (2008), Scour control and surface sediment distribution downstream of block ramps, Journal of Hydraulic Research 46(3), 334-343. 
Pagliara, S., Das, R. and M. Palermo (2008), Scour control and surface sediment distribution downstream of block ramps, Journal of Irrigation and Drainage Engineering 134(4), 527 532.

Pagliara, S., Palermo, M., and I. Carnacina (2009), Scour and hydraulic jump downstream of block ramps in expanding stilling basins, Journal of Hydraulic Research 47(4), 503-511.

Pagliara, S., and M. Palermo (2011), Effect of stilling basin geometry on clear water scour morphology downstream of a block ramp, Journal of Irrigation and Drainage Engineering 137(9), 593-601.

Pagliara, S., Palermo, M., and I. Carnacina (2011), Expanding pools morphology in live-bed conditions, Acta Geophysica 59(2), 296-313.

Pegram, G.G.S., Officer, A.K., and S. Mottram (1999), Hydraulics of skimming flow on modeled stepped spillways, Journal of Hydraulic Engineering 125(5), 500-510.

Peyras, L., Royet, P., and G. Degoutte (1992), Flow and energy dissipation over stepped gabion weirs, Journal of Hydraulic Engineering 118(5), 707-717.

Rajaratnam, N. (1990), Skimming flow in stepped spillways, Journal of Hydraulic Engineering 116(4), 587-591 